\title{
Bleeding Patterns among Severe Hemophilia A and B Patients in West Java
}

\author{
Muhammad Mufakkirul Islam, ${ }^{1}$ Susi Susanah, ${ }^{2}$ Amaylia Oehadian ${ }^{3}$ \\ ${ }^{1}$ Faculty of Medicine Universitas Padjadjaran, Indonesia, ${ }^{2}$ Departement of Child Health \\ Faculty of Medicine Universitas Padjadjaran/Dr. Hasan Sadikin General Hospital Bandung, \\ ${ }^{3}$ Department of Internal Medicine Faculty of Medicine Universitas Padjadjaran/Dr. Hasan Sadikin \\ General Hospital Bandung, Indonesia
}

\section{Abstract}

Background: The clinical manifestations of hemophilia A (HA) and hemophilia B (HB)are quite similar; however, the bleeding characteristics of these two hemophilia types have been reported to be different. This study aimed to explore the bleeding patterns among patients with severe HA and severe HB.

Methods: A cross-sectional study was conducted among patients with severe HA and HB registered at the West Java Indonesian Hemophilia Society. The inclusion criteria were patients with severe hemophilia diagnosed for at least one year. The bleeding patterns included bleeding episodes and bleeding types. The Mann-Whitney test was used to compare bleeding episodes and a chi-square test for bleeding types.

Results: In total, 158 severe HA patients and 21 severe HB patients were included with a median bleeding frequency per patient per year for HA and HB was 24 (range 0-48) and 24 (range 5-48), respectively. The bleeding types in HA and HB were ecchymosis ( $69 \%$ vs. 66.7\%), hematoma ( $62.7 \%$ vs. $61.9 \%$ ), hemarthrosis ( $99.4 \%$ vs. $100 \%$ ), epistaxis (46.8\% vs. $38.1 \%$ ), gum bleeding (87.3\% vs. 95.2\%), intracranial hemorrhage $(15.2 \%$ vs. $9.5 \%)$, multiple hematomas (36.7\% vs. $47.6 \%)$, hemarthrosishematoma (61.4\% vs. 61.9\%), and hemarthrosis-ecchymosis (69\% vs. $61.9 \%$ ). However, there was no significant difference in all types of bleeding between HA and HB.

Conclusions: There is no difference in the pattern of hemorrhage between severe HA and severe HB in West Java. However, the bleeding phenotypes in hemophilia has considerable implications in the therapeutic process. Further research is needed to optimize the treatment regimens.

Keywords: Bleeding episodes, bleeding types, hemophilia A, hemophilia B

\section{Introduction}

Hemophilia is a genetic disease that is inherited by x-linked recessively. Hemophilia is characterized by bleeding abnormalities due to lack of factor VIII or factor IX. ${ }^{1-4}$ When part of the body is injured, the hemostatic process is immediately initiated to protect the integrity of the body and to prevent further bleeding. ${ }^{5,6}$ Plateletactivation at the site of injury is followed by sequential activation of clotting factors and fibrin formation. ${ }^{7}$ Factor VIII and factor IX are essential for thrombin generation and fibrin spread. Circulating Factor VIII is bound to von Willebrand factor (vWF) to protect from proteolytic degradation. Both factor VIII and factor IX are encoded by genes located in the long arm of the $X$ chromosome. When the gene sequence F8 or F9 is interrupted, synthesis of factor VIII/factor IX is reduced or absent, or a less functionally active form is produced. ${ }^{8}$

Some studies have reported that clinical manifestations between hemophilia A (HA) and hemophilia B (HB) do not differ, however, conflicting results might occur such as in bleeding frequency, clinical scores, the need for prophylaxis and the need for joint replacement.9Hemophilia $B$ tends to have milder symptoms than those with hemophilia A, especially in young patients. ${ }^{10}$ An epidemiological study in Scotland has shown that $\mathrm{HB}$ patients have a hospital admission

Correspondence: Muhammad Mufakkirul Islam, Faculty of Medicine, Universitas Padjadjaran, Jalan Raya BandungSumedang Km. 21, Jatinangor, Sumedang, Indonesia, E-mail: mufakkiruli@gmail.com 
rate of 2 to 3 times lower compared to $\mathrm{HA}^{9}{ }^{9}$ In contrast, another study has described that HA has more frequent bleeding frequency compared to HB that is 14.4 times compared to 8.63 bleeding time per patient per year. ${ }^{11}$ The difference in various bleeding phenotypes in hemophilia has considerable implications in the therapeutic process, thus, further research in this area is needed to optimize treatment regimens. ${ }^{9}$

There are around two thousand HA patients registered in the Indonesian Hemophilia Society Association at the end of 2017, of whom this number is only $10 \%$ of the estimated individuals with hemophilia. ${ }^{12}$ The purpose of this study was to explore the bleeding pattern such as bleeding episodes and bleeding types among patients with severe HA and severe HB in West Java.

\section{Methods}

This study was a cross-sectional study using comparative analytical methods. A list of hemophilia patients with severe $\mathrm{HA}$ and $\mathrm{HB}$ in West Java was taken from the Indonesian Hemophilia Society in the period July 2018June 2019. The hemophilia patients must have been diagnosed for at least one year. The data of bleeding episodes when patients had experienced in the last year was collected by calling the patients via mobile phone or by interviewing the patient directly when the patient visited the hospital for control. Further confirmation was asked to assess the type of bleeding experienced such as ecchymosis, hematoma, hemarthrosis, epistaxis, gum bleeding, and intracranial hemorrhage. The interview format from the Indonesian Hemophilia Society West Java was used when calling or interviewing the patients. The Ethics Committee of Universitas Padjadjaran had approved study No. 1248 / UN6.KEP/EC/2019.
The normality test was used to test thedata distribution for age, initial age of diagnosis, and bleeding episodes. The episodes of bleeding were compared using the Mann Whitney test; whereas the type of bleeding between hemophilia A and B was compared using chisquare.

\section{Results}

In total, there were 338 hemophilia patients registered in the West Java Indonesian Hemophilia Society, consisted of 252 severe hemophilia and 86 mild-moderate hemophilia. Of severe hemophilia patients, only 179 were willing to participate, consisting of $158 \mathrm{HA}$ and $21 \mathrm{HB}$; while others were excluded due to inactive mobile phone, death, or relocation of domiciles outside of West Java.

The normality test (Kolmogorov-Smirnov test) showed that the distribution of age and age of diagnosis were not normal distributed, thus median value was used. Furthermore, the data of bleeding episodes among HA and HB was also not normal distributed, thus, the Mann Whitney test was used as shown in Table 1. There was no difference in age between HA and HB (median 14 vs 14 years old; $p$ 0.959). The age of diagnosis in HA was lower than that of $\mathrm{HB}$, however, no statistical difference between HA and HB (median 1.75 vs 3 years old; p 0.204).

There were no differences in bleeding episodes between severe HA and HB (median 24 vs 24; $p$ 0.066). The types of bleeding were presented, and no statistically significant differences in distribution and prevalence among HA and HB (Table 3).

\section{Discussion}

This study is exploring the bleeding pattern such as bleeding episodes and bleeding types

Table 1 Characteristics and Bleeding Episodes of Hemophilia Patients in Dr. Hasan Sadikin General Hospital, West Java, Indonesia

\begin{tabular}{lccc}
\hline \multicolumn{1}{c}{ Type of Hemophilia } & Hemophilia A & Hemophilia B & P-value \\
\hline $\begin{array}{l}\text { Age; years } \\
\quad \text { Median (min-max) }\end{array}$ & $14(2-44)$ & $14(3-50)$ & 0.959 \\
$\begin{array}{l}\text { Age of diagnosis; years } \\
\quad \text { Median (min-max) }\end{array}$ & $1.75(0-22)$ & $3(0-40)$ & 0.204 \\
$\begin{array}{l}\text { Bleeding episodesper year } \\
\quad \text { Median (min-max) }\end{array}$ & $24(0-48)$ & $24(5-48)$ & 0.066 \\
\hline
\end{tabular}


Table 2 Distribution and Prevalence of Bleeding Types among Patients with Severe Hemophilia A and Severe Hemophilia B

\begin{tabular}{|c|c|c|c|c|}
\hline Type of Bleeding & HA & HB & Total & P-Value \\
\hline \multicolumn{5}{|l|}{ Ecchymosis } \\
\hline Yes & $109(69)$ & $14(66.7)$ & $123(68.7)$ & 0.829 \\
\hline No & $49(31)$ & 7 (33.3) & $56(31.3)$ & \\
\hline \multicolumn{5}{|l|}{ Hematoma } \\
\hline Yes & $99(62.7)$ & $13(61.9)$ & $112(62.6)$ & 0.947 \\
\hline No & $59(37.3)$ & $8(38.1)$ & $67(37.4)$ & \\
\hline \multicolumn{5}{|l|}{ Hemarthrosis } \\
\hline Yes & 157 (99.4) & $21(100)$ & $178(99.4)$ & 0.715 \\
\hline No & $1(0.6)$ & - & $1(0.6)$ & \\
\hline \multicolumn{5}{|l|}{ Epistaxis } \\
\hline Yes & $74(46.8)$ & $8(38.1)$ & $82(45.8)$ & 0.450 \\
\hline No & $84(53.2)$ & $13(61.9)$ & $97(54.2)$ & \\
\hline \multicolumn{5}{|l|}{ Gum bleeding } \\
\hline Yes & $138(87.3)$ & $20(95.2)$ & $158(88.3)$ & 0.291 \\
\hline No & $20(12.7)$ & $1(4.8)$ & $21(11.7)$ & \\
\hline \multicolumn{5}{|l|}{ Intracranial bleeding } \\
\hline Yes & $24(15.2)$ & $2(9.5)$ & $26(14.5)$ & 0.489 \\
\hline No & $134(84.8)$ & $19(90.5)$ & $153(85.5)$ & \\
\hline \multicolumn{5}{|l|}{ Hematoma multiple } \\
\hline Yes & $58(36.7)$ & $10(47.6)$ & $68(38)$ & 0.333 \\
\hline No & $100(63.3)$ & $11(52.4)$ & $111(62)$ & \\
\hline \multicolumn{5}{|l|}{ Hemarthrosis-Hematoma } \\
\hline Yes & $97(61.4)$ & $13(61.9)$ & $110(61.5)$ & 0.964 \\
\hline No & $61(38.6)$ & $8(38.1)$ & & \\
\hline \multicolumn{5}{|l|}{ Hemarthrosis-Ecchymosis } \\
\hline Yes & $109(69)$ & $13(61.9)$ & $69(38.5)$ & 0.513 \\
\hline No & $49(31)$ & $8(38.1)$ & $57(31.8)$ & \\
\hline
\end{tabular}

among patients with severe HA and severe HB in West Java. The bleeding patterns in hemophilia have considerable implications in the therapeutic process. ${ }^{9}$ The median age of patients with both severe HA and HB in West Java registered in the Indonesian Hemophilia Association is 14 years old. These results are different when compared with the median age in other studies, of whom for HA and HB is 23 years old and 28 years old, respectively. ${ }^{11}$ It seems that HA is younger and HB; whereas in our study the median age of the patients is very young. Furthermore, there is no difference in bleeding episodes. In a study published earlier, within a period of 36 months, hemophilia A patients might have 2,800 hemorrhage episodes, whereas hemophilia B has 502 hemorrhage episodes. Beside, severe HA has 1,491 joint hemorrhages, and in severe HB has 332 joint bleeding. This study also shows that bleeding episodes in hemophilia $\mathrm{A}$ are more than hemophilia $B$, which is 14.4 vs 8.63 bleeding/patient/year, respectively. ${ }^{11}$ The differences in the results in our study on the median age and bleeding episodes might be due to the effect of prophylactic administration 
and more equitable replacement factors in the developed countries. In addition, factors that can affect the number of episodes of bleeding in patients including nutritional status, ${ }^{13}$ the severity of coagulation factor deficiency, genetic factors, and the formation of inhibitors. ${ }^{14}$ Further research on differences in bleeding patterns by considering those confounding factors need to be done. The limitation of this study is the recall bias that may occur in patients or the family members interviewed.

Furthermore, there are no significant differences in the clinical manifestations of the bleeding episode and bleeding type between severe hemophilia A and B patients in West Java. A previous study has shown the same result. ${ }^{15}$ However, intracranial hemorrhage as a manifestation of the bleeding type which is quite severe and the biggest cause of death in people with severe hemophilia has a percentage of events almost 2-fold greater in hemophilia A when compared with hemophilia B (15.2\% vs $9.5 \%) .{ }^{16}$

In conclusion, there is no difference in the pattern of hemorrhage between severe HA and severe HB in West Java, however, the bleeding phenotypes in hemophilia have considerable implications in the therapeutic process. Further research is needed to optimize treatment regimens.

\section{References}

1. Srivastava A, Brewer AK, MauserBunschiten EP, Key NS, Kitchen A, Llinas A, et al. Guidelines for the management of hemophilia. Haemophilia. 2013;19(1):e147.

2. Rambe IK, Sungkar E, Moeliono MA, Astini S. Prediction of hemophilia joint health score based on age and disease severity of hemophilia A and B with on demand therapy in West Java. Malays J Paediatr Child Health. 2018;24(2):1-10.

3. Berntorp E, Shapiro AD. Modern haemophilia care. Lancet. 2012;379(9824): 1447-56.

4. Potgieter JJ, Damgaard M, Hillarp A. One-stage vs. chromogenic assays in haemophilia A. Eur J Haematol. 2015; 94(Suppl 77):38-44.

5. Gale AJ. Continuing education course \#2: current understanding of hemostasis. Toxicol Pathol. 2011;39(1):273-80.

6. Versteeg HH, Heemskerk JWM, Levi M, Reitsma PH. New Fundamentals in Hemostasis. Physiol Rev. 2013;93(1):32758.

7. Periayah MH, Halim AS, Saad AZM. Mechanism action of platelets and crucial blood coagulation pathways in hemostasis. Int J Hematol Oncol Stem Cell Res. 2017;11(4):319-27.

8. Fijnvandraat K, Cnossen MH, Leebeek FWG, Peters M. Diagnosis and management of haemophilia. BMJ. 2012;344:e2707

9. Santagostino E, Fasulo MR. Hemophilia A and hemophilia B: Different types of diseases? Semin Thromb Hemost. 2013; 39(7):697-701.

10. Mannucci PM, Franchini M. Is haemophilia $B$ less severe than haemophilia A? Haemophilia. 2013;19(4):499-502.

11. Nagel K, Walker I, Decker K, Chan AKC, Pai MK. Comparing bleed frequency and factor concentrate use between haemophilia A and B patients. Haemophilia. 2011;17(6): 872-4.

12. World Federation of Hemophilia. Annual Global Survery 2017. Canada: World Federation of Hemophilia; 2018.

13. Biere-Rafi S, Haak BW, Gerdes VEA, Büller HR, Kamphuisen PW. The impairment in daily life of obese haemophiliacs. Haemophilia. 2011;17(2):204-8.

14. Peyvandi F, Garagiola I, Young G. The past and future of haemophilia: diagnosis, treatments, and its complications. Lancet. 2016;388(10040):187-97.

15. Longo DL, Fauci AS, Kasper DL, Hauser SL, Jameson JL, Loscalzo J, editors. Harrison's principles of internal medicine. $18^{\text {th }} \mathrm{Ed}$. New York: McGraw-Hill Professional; 2012.

16. Escobar M, Sallah S. Hemophilia A and hemophilia B: Focus on arthropathy and variables affecting bleeding severity and prophylaxis. J Thromb Haemost. 2013;11(8):1449-53. 